\title{
Evaluation of a hypermedia maintenance support application
}

\author{
Richard Crowder*, Gary Wills, Wendy Hall \\ IAM Group, Department of Electronics and Computer Science, University of Southampton, \\ Southampton SO17 1BJ, UK
}

Received 14 May 2002; accepted 1 February 2003

\begin{abstract}
A large hypermedia application has been developed to demonstrate the concept of factory wide hypermedia to support the maintenance of a major process line. As part of its development cycle, the performance of the software and its acceptance by the user community has been fully evaluated. The evaluation method considered in this paper focuses on the subjective opinion of the users and measured the ease with which users could retrieve the information required to perform specific tasks, and is considered suitable for other large industrial hypermedia applications. This research draws together standard evaluation techniques into a methodology for evaluating an industrial strength hypermedia application. The trials undertaken showed that the users were able to find the identical information in approximately one-third of the time when using the hypermedia system, over a paper-based system, which equate to a significant cost savings during unscheduled maintenance periods.
\end{abstract}

(C) 2003 Elsevier Science B.V. All rights reserved.

Keywords: User evaluation; Open hypermedia; User interface; Manufacturing

\section{Introduction}

As manufacturing systems increase in sophistication and complexity, a considerable amount of information is required for plant operation and maintenance. An effective information management system for factory floor applications must not only manage a range of document types, but it must also make it easy for any user to follow the interrelationship between pieces of information. A hypermedia information system presents users with a range of options, from which they are able to determine the order in which the documents are studied. In effect the

\footnotetext{
* Corresponding author. Tel.: +44-23-8059-3441; fax: +44-23-8059-2865.

E-mail address: rmc@ecs.soton.ac.uk (R. Crowder).
}

author gives the user a number of alternate routes through the resources.

The acceptance of information technology is greatly influenced by the user interface, particularly where non-computer specialists are concerned. To gain information regarding usability and benefits, a robust evaluation procedure is required which is specifically tailored to industrial application. In this paper, previously used evaluation methodologies are refined to produce a methodology for evaluating the usability of hypermedia applications in the industrial environment. The methodology has been applied to industrial hypermedia application developed for a cable process line located at a UK site of the multinational company, Pirelli Cables. In order to verify the evaluation methodology, a second company The Ford Motor Company, operating in a 
different industrial sector, supplied a number of users for the trials.

\subsection{The industrial hypermedia application}

The concept of using open hypermedia for information and document management within manufacturing organisations was proposed by Malcolm et al. [1], who argued that hypermedia systems had to evolve beyond the stand alone application and allow the integration of resources across an enterprise. A number of hypermedia applications including engineering applications [2-4], medical record keeping [5], historical archives [6], and education [7] have been reported.

The industrial hypermedia application considered in this paper was developed as part of the Factory Information Resource Management (FIRM) project using Microcosm [8,9]. Microcosm ${ }^{1}[10]$ is an open hypermedia system, where the links are stored separately from the documentation and through filtering processes are brought together when the user views the document. Microcosm has the concept of a generic link or glossary link, which is an association made from an object at any position in any document to a particular object in a destination document. In addition, compute links which are dynamically computed when requested, and a guided tour that takes the user through a set of documents, are also features of Microcosm.

The FIRM project moved away from a monolithic application to a modular approach for hypermedia development, by using Modular Hypermedia Applications (MHAs) [11]. An MHA is based on the principle where a large problem can be more easily managed by decomposing it into smaller modules that are more easily dealt with. This approach can be applied to the information domain, resulting in the large information space being broken down into smaller hypermedia applications, for the ease of handling and authoring. An authoring environment then compiles the individual MHA into a single application for delivery.

As previously reported [12], the application was developed for a supertension cable sheathing line at a local site of a major multinational. The $90 \mathrm{~m}$ long line extrudes the cross-linked polyethylene outer-sheath

\footnotetext{
${ }^{1}$ Microcosm is available from Active Navigation, http:// www.multicosm.com.
}

onto a supertension cable. ${ }^{2}$ In addition to the extruder the line includes a bitumen tank, drive systems, cooling tank, spark tester and pay-off and take-up stands. The line can take cable drums up to 50 tonnes containing cables up to $155 \mathrm{~mm}$ diameter, and $40-50 \mathrm{~kg} \mathrm{~m}^{-1}$ in weight. Due to the scope of the application the development of the hypermedia application not only involved operating company, but also the line builder and a number of their suppliers both in the UK and across Europe. In order for hypermedia systems to be used widely in industry, the hypermedia application must operate enterprise wide, and not solely concern an isolated piece of equipment. The solution, in part, is the incorporation into the hypermedia system additional functionality, such as the ability to query remote information systems and have a direct interface with the equipment, allowing the hypermedia system to provide the correct supporting information, depending on the equipment's status (Fig. 1).

At the conclusion of the project, the information resource base comprised of 850 nodes in 26 MHA, equating to over 640 Mbytes of information. Over 4500 links had been produced and were held in over 70 linkbases. Fig. 2 shows the wide range of materials available to the user during a maintenance procedure. This includes not only the information specific to the line either in text or engineering drawings, but also access to company wide information on processes and safety. One of the advantages of this approach is the ability to directly link from the list of spares to the company's stores database, hence reducing the time and error associated with manually ordering a component.

The industrial environment brings together users with different and varying computer skills, all of whom need to be supported. Many interfaces for industrial applications try to provide a common look and feel by providing the same user interface for all applications and user groups. In our view, and that of our user community, what is actually required is an appropriate interface for the task that has a common look and feel, yet allows different groups of users, with different abilities, access to the appropriate information. As with many processes running in Microsoft Windows environment, a number of application interfaces can be on the screen at the same time.

\footnotetext{
${ }^{2}$ Supertension cables are typically rated in excess of $250 \mathrm{kV}$.
} 


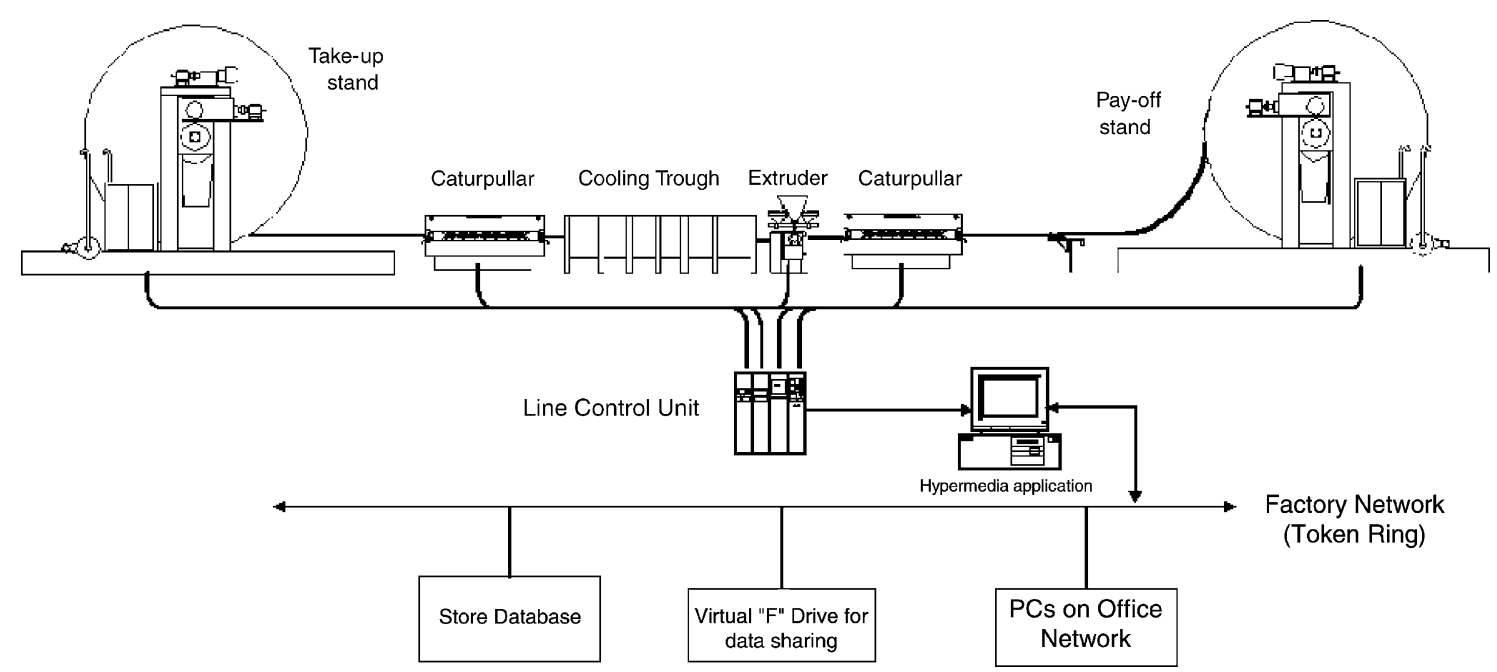

Fig. 1. Supertension sheathing line, showing the hypermedia system and its interconnection to external resources and the line.

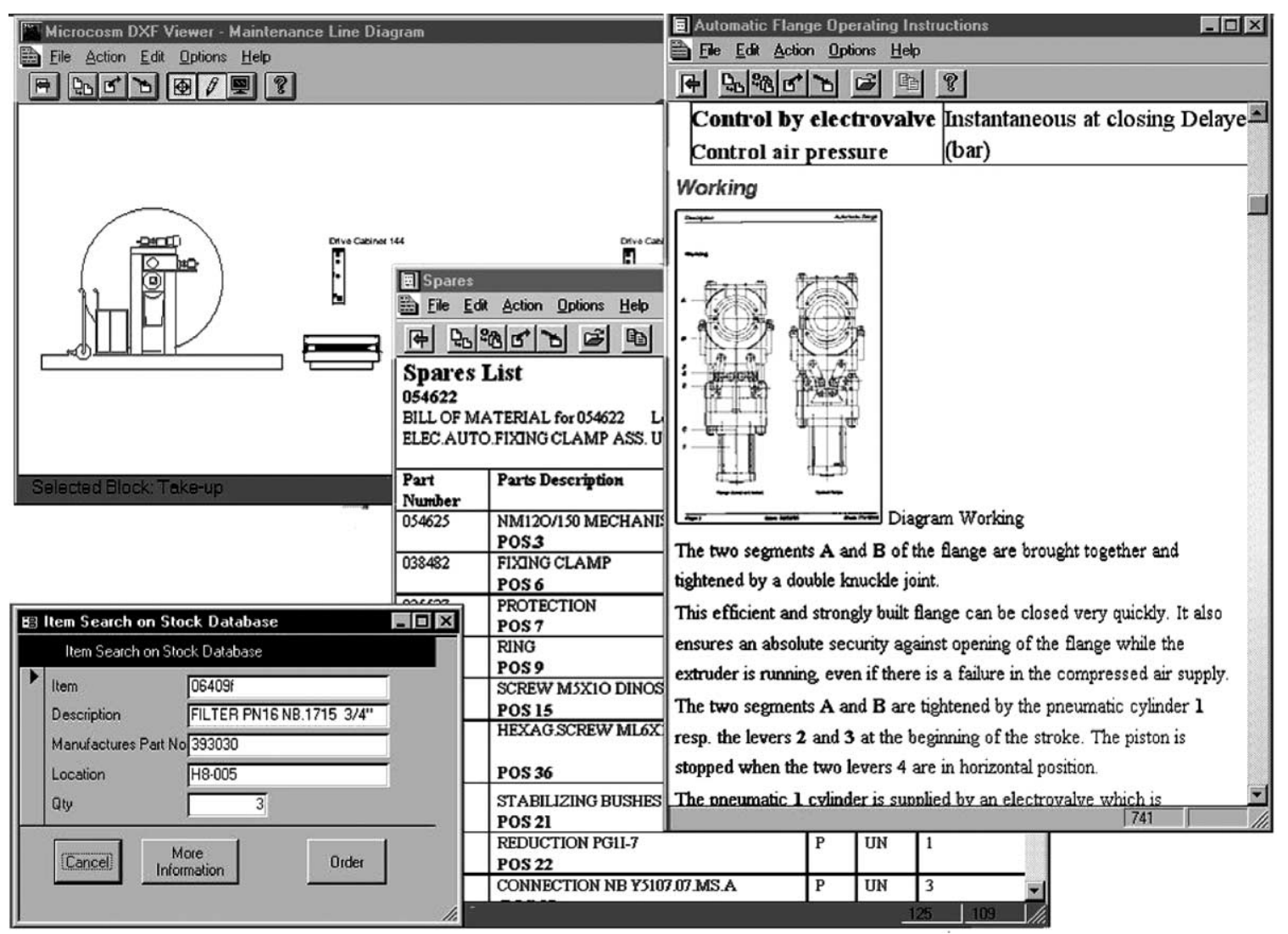

Fig. 2. Typical maintenance information, including detailed operating instruction for a valve (right), spares list (center), access to the store's stock database (lower left) and line schematic (top left). 
The interfaces all act independently of each other in terms of screen management and can therefore be made to overlap or obscure one another; which may cause problems to inexperienced users. One approach is to provide a fixed window layout, however this approach would be very restrictive when applied to the applications envisaged by this work. For this reason, FIRM used the Screen Handler Enabling Process (SHEP) designed and implemented by Hall et al. [13]. SHEP uses an architecture that promotes the disclosure of state information by the individual processes and allows screen management processes to modify the interface as required by the user.

\subsection{Evaluation of an industrial hypermedia application}

As part of the development process, formal evaluation is required which is concerned with gathering of information about the usability of a system, in order to improve features or to assess the interface [14-16]. The evaluation discussed in this paper was used to assess the application against the following criteria:

- The efficiency with which users can successfully navigate through the hypermedia documentation.

- The effectiveness of the system in allowing users to locate a correct document or specified point within a document.

- The ability with which users can begin to make effective use of the application, by incorporating it into their daily activities.

- Acceptance by the user of the hypermedia system into their daily activities.

- Identification of features that aid or hinder the task being undertaken.

The evaluation discussed in this paper only addresses information delivery and not impact of hypermedia on the users ability to undertake a task. The evaluation methodology needs to consider the practical aspects (for example, taking personnel from the factory floor for an extended period of time) and the cost of undertaking the evaluation to the company. Due to the availability of resources within the organisations, the traditional experimental usability evaluations involving specialist usability facilities are not considered an option.
The application discussed in this paper was specifically evaluated to examine the following hypotheses:

\section{Hypothesis 1.}

HO Retrieving the information using the hypermedia system is no quicker than using a paper-based system.

H1 Retrieving the information using the hypermedia system is quicker than using a paper-based system.

\section{Hypothesis 2.}

H0 The hypermedia system is no easier to use than the paper-based system.

H1 The hypermedia system is easier to use than the paper-based system.

In addition, the following system goal was developed in association with senior management at Pirelli Cables:

... to improve the operators and maintainers retrievability of a document by using the open hypermedia documentation system, over the current paper-based system, through ease of use, by a reduction of at least $10 \%$ in the time to locate a specific document ...

This threshold was based on the company's experience, where a small reduction in unplanned maintenance time would result in a substantial cost saving and was developed using a Goal-Question-Matrix approach, [17-19].

\section{Hypermedia evaluation}

The majority of the literature on evaluating hypermedia applications focuses on application domains other than manufacturing, for example, museum and educational applications. However, Kosky et al. [20] have investigated the effect of training factory floor operators to perform tasks using a hypermedia application. The results showed an increase in the knowledge learnt and a slight decrease in the time taken to perform the tasks when compared to paper-based information. Fankun and Greeenough [21] have also undertaken evaluations based on work by Davis [22] to 
measure the behavioral intention, of factory floor personal, towards using a closed hypertext system. The results show that in general the users were favourably disposed to using this technology to support the maintenance of large automated systems within a manufacturing company, or to support the assembly of consumer electronics. Currently, there is no reported hypermedia usability evaluation methodology that has been developed specifically for industrial hypermedia application. However, Garzotto and Paolini [23] have proposed a framework for the Systematic Evaluation of Hypermedia (SUE) that basically combines inspection with empirical testing in two phases:

- Preparatory phase: during which the evaluation process will be developed.

- Evaluation phase: involving both expert and user evaluations, the results being fed back as part of the design process.

SUE was originally designed using the Hypermedia Design Methodology (HDM) for museum applications. While superficially similar to our application, a museum application has significant differences, including a focus on education, lack of robustness and low risk if the information is incorrect. The evaluation process developed by Garzotto and Paolini [23] cannot be directly applied to applications that are not based on HDM, due to the close interrelationship between SUE and HDM. However, the principles distilled from the preparatory phase of the SUE methodology included approaches to the:

- development of the definitions for the hypermedia model and the design criteria;

- definition of the application's usability criteria;

- definition of the tasks to be used in the evaluation process.

If this approach is taken for the evaluation of largescale industrial applications, care needs to be taken that the tasks are defined and the language used is appropriate to an industrial environment [15,24]. An approach to resolving some of these issues was discussed by Höök who considered the evaluation of adaptive hypermedia as applied to an electronic manual [25].

As the time and personnel resources available within Pirelli Cables and Ford to undertake the required evaluations were limited, an evaluation methodology was developed based on a number of commonly used techniques. The limited resources available require the use of a structured expert review [16], and in particular discounted usability evaluation. This is a heuristic approach proposed and refined by Nielsen and coworker [26-28]. Discounted usability evaluation can be carried out using limited resources and a small number of participants, typically 6-10. Any increase in numbers over this will not produce any significant benefit. The process consists of the following activities:

- A limited number of small easily modified scenarios used to test aspects of the system.

- Informal thinking aloud, where the evaluators are asked to articulate their thoughts.

- Heuristic evaluation to alleviate highlighted problems by a modify-evaluate-modify cycle.

One of the advantages of the discounted usability method is that the majority of application errors can be found without having to waste end users' time. However, the method does rely on the ability of experts to judge the participant's reactions, hence, not all the problems will be found.

\section{Methodology for evaluating industrial hypermedia}

The approach taken in the evaluation process for an industrial hypermedia application required five activities: contextual review, structure expert review of the prototype, training with initial feedback, usability trials and continuing evaluation [8].

The application's main elements mapped against the essential features of the application are shown in Table 1, for example, the Modular Hypermedia Application directly influences the applications Structural design and Navigation. This will allow the evaluation process to directly inform the design of specific elements of the application. Garzotto and Paolini [23] emphasised that the design used for the application will influence the evaluation and help provide a common language and definitions for the tasks undertaken by the users. In addition to the design attributes, a number of usability criteria are required to define interaction with the application, these are defined in Table 2. 
Table 1

The design's elements mapped against the application's essential features

\begin{tabular}{llll}
\hline Elements & \multicolumn{2}{l}{ Essential features } \\
\cline { 2 - 4 } & Structural & Navigation & Presentation \\
\hline $\begin{array}{l}\text { Modular Hypermedia } \\
\quad \text { Application }\end{array}$ & $\checkmark$ & $\checkmark$ & \\
Nodes & & & $\checkmark$ \\
Structural Links & $\checkmark$ & $\checkmark$ & \\
Clusters & & $\checkmark$ & \\
Screen control & & & $\checkmark$ \\
Menu & & $\checkmark$ & $\checkmark$ \\
Toolbox & & $\checkmark$ & \\
Results box & & $\checkmark$ & $\checkmark$ \\
Guided tours & $\checkmark$ & $\checkmark$ & \\
\hline
\end{tabular}

The questionnaires used in the evaluation process were designed to measure the scale of: Impression, Command, Effectiveness, Learnability, Aidability, Navigability and Comprehension, as defined in Table 3. The first five scales are based on The Software Usability Measurement Inventory [29], with Navigation and Comprehension, added to specifically measure issues in industrial hypermedia applications.
The design of the questionnaire was such that participants were forced to make a choice, as there was no neutral answer. A positive response to a positively phrased question scored +1 (agreed) and +2 (strongly agreed), a negative response to a positively phrased question was scored score -1 (disagreed) and -2 (strongly disagree). The reverse being true for the responses to negatively phrased questions. The questionnaires used after training and a usability trial are given in Appendices A and B, respectively.

\subsection{Contextual review}

A contextual review of working practices in the target environment was undertaken prior to the development of the prototype. The results from Pirelli Cables, identified the following perceived benefits for hypermedia within the industrial domain:

- Ensuring that all operators and maintainers have access to the current information at all times.

- Reduction in time required to locate the correct information.

Table 2

Usability criteria

\begin{tabular}{ll}
\hline Criteria & Definition \\
\hline $\begin{array}{l}\text { Retrievability } \\
\text { Orientation }\end{array}$ & $\begin{array}{l}\text { How easily a user can find the relevant information } \\
\text { The ability of the users to know their current location relative to supporting information, the information context } \\
\text { and the ease with which they can return to a position }\end{array}$ \\
$\begin{array}{l}\text { Reuse } \\
\text { Intuitive }\end{array}$ & $\begin{array}{l}\text { Can the user grasp the meaning and purpose of the information, dialogue box, window, etc. that is being presented } \\
\text { Consuring that conceptually similar elements are treated in an identical fashion, while different elements are } \\
\text { clearly differentiated }\end{array}$ \\
Accessibility & How accessible with or without the correct permissions is the information
\end{tabular}

Table 3

Questionnaire scales and definitions

\begin{tabular}{ll}
\hline Scale & Definition \\
\hline Impression & The users feelings or emotions when using the software \\
Command & The measure to which the user feels that they are in control \\
Effectiveness & Degree to which the user feels that they can complete the task \\
Aidability & Degree to which the application assists the user to resolve a situation \\
Learnability & Degree to which the user feels that the application is easy to become familiar with \\
Navigability & Degree to which the user can move around the application \\
Comprehension & Degree to which the user understood the interaction with the application
\end{tabular}


- Providing additional background information only when necessary.

- Reduction in the production and distribution costs associated with controlled copies.

\subsection{Structured expert review of the prototype}

As part of the development cycle associated with the hypermedia maintenance support application, a structured expert review was conducted, with experts being selected from staff responsible for the Supertension sheathing line. This ensured that the comments on the user interface and information content were relevant to the end users [8]. The review showed that:

- A toolbar was an effective method of providing short cuts.

- A pictorial representation of a process line was an effective gateway to resources.

- The traditional fixed-page screen format was too restrictive for a factory floor hypermedia interface, with the SHEP [13] methodology providing some of the solutions.

The review also revealed that while navigating a large information space it is easy for a user to get disoriented. The system must provide users with utilities to navigate the information space without getting lost. Hence, evaluation of a large hypermedia system needs to explicitly assess the level to which the system provides navigational aids. To address this point, an additional heuristic, identified as provide navigational aids, was included in the evaluation.

\subsection{Training with initial feedback}

After a training programme to introduce the uses to the hypermedia technology and this specific application, users were asked to complete a questionnaire to discover their initial opinion of the application. This approach encouraged users to give their opinion, albeit subjectively during the latter part of the design phase, therefore giving them a degree of ownership and ensuring that the application met their needs at the earliest possible opportunity.

\subsection{Usability trials}

Usability trial, where predefined tasks developed in association with the line's management team, were completed using the hypermedia application. The results from the trials were used to evaluate the effectiveness of the application. These tasks were analysed using a range of metrics, including time to complete the task, and number of nodes visited.

\section{The evaluation of the supertension hypermedia application}

After training 21 users at Pirelli Cables, two usability trials were undertaken approximately 3 and 9 months after training. Four members of the management team, 6 operators, 11 maintenance technicians and 2 apprentices were trained. In addition, 9 personnel from Ford were also trained to use the system.

\subsection{User profiles}

Table 4 gives details of the trial participants, who in this case were all males. The table also identifies the computing system they use at work (either a personnel computer (PC) or special purpose computers associated with the line (line)) and whether they can programme to the level of spreadsheet macros.

Table 4

User profiles

\begin{tabular}{|c|c|c|c|c|c|c|}
\hline & \multirow[t]{2}{*}{ Number } & \multicolumn{3}{|l|}{ Age } & \multicolumn{2}{|c|}{ Computing skills } \\
\hline & & Range & Mean & $\sigma$ & Systems & Programming \\
\hline Pirelli management & 4 & $30-55$ & 45 & 10 & $\mathrm{PC}$ & Yes \\
\hline Pirelli technicians & 11 & $18-60$ & 42 & 13.5 & $\mathrm{PC}$ & No \\
\hline Pirelli operators & 6 & $26-60$ & 46 & 9.2 & Line & No \\
\hline Apprentices & 2 & 18 & 18 & 0 & PC & No \\
\hline Ford staff & 9 & $18-50$ & 35 & 8.5 & $\mathrm{PC}$ & No \\
\hline
\end{tabular}




\subsection{Comments raised during training}

The following specific points raised during training indicated a need to change both information delivery and working practice:

- All users asked that the electronic information was available at the point of use, through the use of mobile computing technology [30].

- The maintainers wanted to be able to annotate drawings with changes or modifications, to provide a permanent record, and allow dissemination of best maintenance practice.

- The maintainers wanted more detailed equipmentspecific information that went beyond what they had in any paper-based system. Hypermedia allows information to be tailored more closely to the application [31], and can through the adaptive systems allow the real time adaptation of documentation to satisfy the users immediate needs.

- The hypermedia system with a suitable interface would allow the maintainers to keep other records more conveniently, resolving the problem of misplacing handwritten notes.

- The users would like to publish or disseminate to other users useful trails through the information space [32], allowing users to share their experiences, leading to a more efficient use of the documentation system.

- There were concerns relating to the amount of information that could be displayed and still be legible.

The operators and maintainers had worked on the process line since it was installed, prior to the introduction of the hypermedia application, consequently, they have seen many of the faults and problems before, and hence their comments on the application may have been influenced by the familiarity with the line.

\subsection{Results from the post-training questionnaires}

Twenty-three questionnaires from the 30 distributed across both organisations were returned immediately after the training sessions. Fig. 3 shows the normalised scores. It was clear that users had a positive impression of the system, in particular:

- Nobody agreed with the statement that the system was demanding and not enjoyable to use, and $70 \%$ of the users would recommend the system.

- All users felt that the system was effective in retrieving the required information. All users found

\$ Pirelli EFord EALL

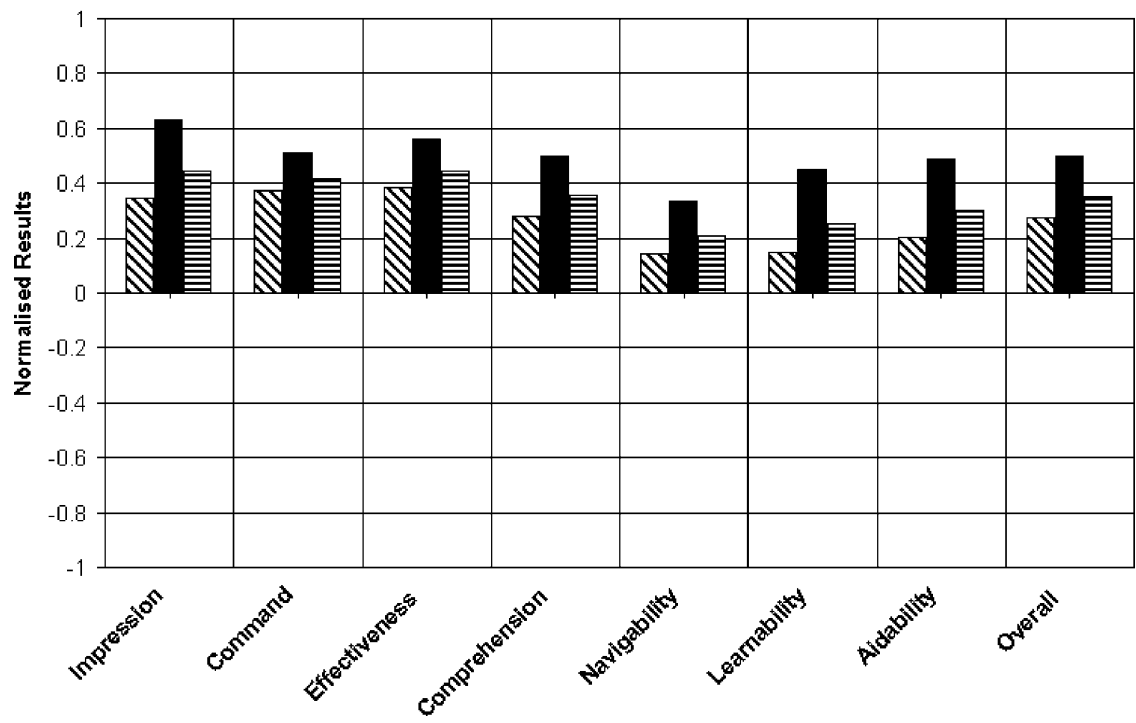

Fig. 3. User opinion of the system after training. 
the information they required, with $91 \%$ indicating that it was straightforward. However, $22 \%$ of users thought that there were too many steps to get specific information.

- All users found the information to be clearly presented, understandable and consistent, though $26 \%$ considered that too much text was displayed at any one time.

- The user perception of the aidability was high, though $26 \%$ thought that the system was awkward to use when undertaking an unfamiliar task. Similarly, $43 \%$ of users felt safer keeping to a familiar method of retrieving information.

- In the evaluation, $78 \%$ of the users found it easy to navigate the information, with $87 \%$ finding a wide range of routes to get to the information they required. However, $43 \%$ of users felt that it was easy to become disorientated when using the system.

- The difference in results from the Pirelli and Ford users was noticeable, this was largely due to the Pirelli personal being very familiar with the line and its documentation leading them to be over critical to content and context. The Ford personnel who were not familiar with the line considered the application from a more conceptual viewpoint.

\section{Usability trials}

The objective of the usability trials was to measure the effectiveness and ease of using a hypermedia application to locate information and not the fault finding abilities of the maintainers. The usability trials reflected this objective, and only recorded the time and number of nodes taken to locate a specific piece of information. The initial usability trials were undertaken approximately 6 months after training to allow the users to gain experience of the system. The usability trials were of a single factor design [33], the single factor being the information resources used with two variables, electronic information or paper. The tasks in Table 5 were specific in their description and were developed with and approved by the line's senior maintenance engineer. The tasks developed reflected actual activities conducted infrequently on the line, while being well defined they were not highly specific. In addition, a mixture of mechanical and electrical tasks were provided to reflect the skills of the line's maintainers. The task definitions provided uniformity in the evaluation process, especially when different evaluators were involved.

The order in which the maintainers performed the tasks, and whether they carried out a task with the paper system first or the hypermedia system, was randomised to balance out any learning effect. An observer watched each subject undertake the tasks, recording the time, the number of documents visited, the number of content or index pages used, and the number of times they became lost to complete the task. The observer recorded the observation on a tape recorder, so they could freely move around the factory floor. On completion of the tasks the user completed the questionnaire.

Table 5

Usability trials tasks

\begin{tabular}{|c|c|c|c|c|}
\hline Task & Description & Comment & Criteria $^{a}$ & Design elements ${ }^{\mathrm{a}}$ \\
\hline E1 & $\begin{array}{l}\text { A heating element is not working. Locate the } \\
\text { drawings showing connections }\end{array}$ & $\begin{array}{l}\text { Using company-specific information, } \\
\text { drawing list and toolbar }\end{array}$ & & SHEP \\
\hline E2 & $\begin{array}{l}\text { Pay-off drive will only jog backwards. } \\
\text { Identify the relay and its location }\end{array}$ & Uses links in bitmap drawings & Reuse & SHEP clusters \\
\hline E3 & $\begin{array}{l}\text { No power to the compressed air system, } \\
\text { locate connections }\end{array}$ & & Consistence & SHEP \\
\hline M1 & Locate extruder assemble instructions & Straight text search & Consistence & Results box \\
\hline M2 & $\begin{array}{l}\text { Locate the information concerning changing } \\
\text { the belt on the cable drive }\end{array}$ & Reference drawings from the text & Reuse & Clusters \\
\hline M3 & $\begin{array}{l}\text { Find the part number of the extruder's } \\
\text { feed pipe filter and its associated drawing }\end{array}$ & $\begin{array}{l}\text { Moving between text, drawing } \\
\text { and parts list }\end{array}$ & Reuse & SHEP \\
\hline
\end{tabular}

${ }^{\text {a }}$ All tasks consider Modular Hypermedia Applications, Nodes, Structured Links, Menu, and Toolbox under 'Design elements' as defined in Table 1, and Retrievability, Orientation and Intuitive under 'Criteria' as defined in Table 2. 
Table 6

Summary of the usability trial results

\begin{tabular}{llrrl}
\hline Task & Media & \multicolumn{2}{c}{ Time $(\mathrm{s})$} & Significance $^{\mathrm{a}}$ \\
\cline { 3 - 4 } & & \multicolumn{1}{c}{ Mean } & \multicolumn{1}{c}{} & \\
\hline Electrical & Paper & 176.75 & 102.71 & $P<0.01$ \\
& Hypermedia & 65.71 & 24.13 & \\
Mechanical & Paper & 123.27 & 55.49 & $P<0.001$ \\
& Hypermedia & 39.73 & 13.70 & \\
All tasks & Paper & 147.04 & 82.79 & $P<0.001$ \\
& Hypermedia & 51.04 & 22.66 & \\
\hline
\end{tabular}

${ }^{\mathrm{a}}$ Measured by $t$-test.

\subsection{Results from the usability trial}

Table 6 shows that the mean time to locate information using the hypermedia system was approximately one-third of the time taken when using the paper-based system. When analysing the entire group together this time difference is highly significant. Hence, the hypothesis that "retrieving information using the hypermedia system is quicker than using the paperbased system" was proven. Table 7 shows task usability data where only pages that the users dwelt on for a period of time were counted as being visited, as a result the number of documents actually visited was higher than recorded. Even with the possible underestimation for the paper-based system, the user obtained the information by visiting fewer documents than when using the hypermedia application. Similarly, on average, users spent less time on each document.
Coupled with users taking fewer incorrect paths and using the short cuts and menus more effectively, it is possible to conclude that the user found the hypermedia system easier to use. This was reflected in the response to the questions in the questionnaires to ascertain how the user compared the ease of use of the two systems (Table 8). Hence, a further hypothesis that "the hypermedia system is easier to use than the paper-based system" can be accepted.

The results from the usability trial questionnaire completed showed an increase in each category compared to the results after the initial training (Fig. 4). The increased normalised scores from the questionnaires after the usability trials suggest that the real benefits of using the hypermedia system only become apparent to the users when they could place the use of the hypermedia system in the context of their working environment and whilst undertaking tasks they could relate to.

\subsection{Second usability trial}

The usability trials were repeated to ensure that the results obtained were still valid after a period of approximately 6 months of normal usage. During this period the users did not receive any assistance or input from the design team. Following restructuring at the company, only five of the original nine maintainers were available to carry out this second trial, together with the promoted senior apprentice. The procedures, questionnaires and tasks remained unchanged from the first trial.

Table 7

Task usability data from the first usability trial

\begin{tabular}{|c|c|c|c|c|c|}
\hline & & Mean & $\sigma$ & Median & Significance $^{a}$ \\
\hline \multirow[t]{2}{*}{ Documents visited } & Paper & 12.4 & 5.89 & 11.00 & \multirow[t]{2}{*}{$P<0.001$} \\
\hline & Hypermedia & 5.2 & 1.2 & 5 & \\
\hline \multirow[t]{2}{*}{ Time (s) spent on location and studying each document } & Paper & 11.49 & 6.42 & 11.5 & \multirow[t]{2}{*}{$P<0.001$} \\
\hline & Hypermedia & 10.19 & 3.11 & 10 & \\
\hline \multirow[t]{2}{*}{ Number of occasions the user became lost } & Paper & 0.44 & 0.64 & 0 & - \\
\hline & Hypermedia & 0.04 & 0.19 & 0 & - \\
\hline \multirow[t]{2}{*}{ Number of short cuts and indexes used } & Paper & 1.33 & 1.07 & 1.00 & - \\
\hline & Hypermedia & 2.37 & 1.21 & 2.00 & - \\
\hline Links used & Hypermedia & 3.75 & 1.22 & 4 & - \\
\hline
\end{tabular}

\footnotetext{
${ }^{\mathrm{a}}$ Measured by $t$-test.
} 
Table 8

Summary of questionnaire response after the usability trial

\begin{tabular}{lccc}
\hline Question & Total scores & \\
\cline { 2 - 3 } & Paper & Hypermedia & Significance $^{\mathrm{a}}$ \\
\hline I would want to use the application on a regular basis & -6 & 11 & $P<0.001$ \\
It was not frustrating to use & -7 & 10 & $P<0.001$ \\
I found it straightforward to get to information & -9 & 9 & $P<0.001$ \\
There are too many steps required to get to information & -12 & 9 & $P<0.001$ \\
It would not get in the way of the task I was undertaking & -8 & 9 & $P<0.001$ \\
I did not find it difficult to obtain the information & -5 & 7 & $P<0.001$ \\
I did not become lost/disoriented when using the system & -7 & 7 & $P<0.001$ \\
Total & -54 & 62 & 0.86 \\
Normalised & -0.75 &
\end{tabular}

${ }^{\text {a }}$ Significance computed using Wilcox signed rank test.

The results from the second usability trial show that a continuing statistically significant difference between using the paper-based information system and the hypermedia system was present. The users were continuing to find the information quicker using the hypermedia system (Table 9). When using the hypermedia system the users again visited less documents in order to find the information (Table 10). In addition, none of the users got lost while using the hypermedia system. However, a number of users found it difficult to obtain information without some assistance when using the paper-based system. The response to the questionnaires continued to show that the users preferred the hypermedia system to the current information system (Table 11). In addition, the normalised scores from the questionnaires increased (Fig. 4). Hence, both hypotheses can still be considered to be proven.

\$ After Training $\square$ First usability trial E Second usability trial

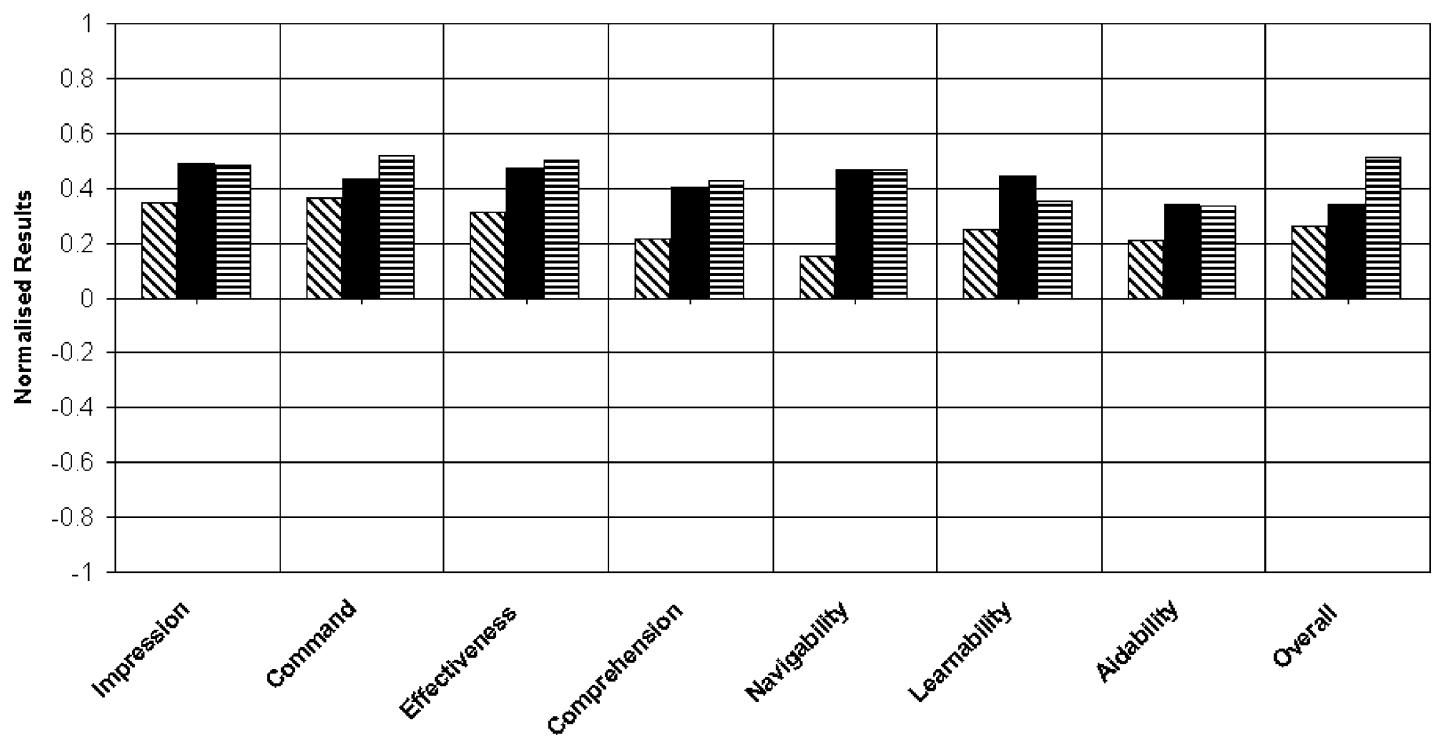

Fig. 4. Summary of the questionnaire results following the individual trials. 
Table 9

Summary of the second usability trial

\begin{tabular}{llccl}
\hline Task & Media & \multicolumn{2}{c}{ Time $(\mathrm{s})$} & \multirow{2}{*}{ Significance } \\
\cline { 3 - 4 } & & Mean & $\sigma$ & \\
\hline Electrical & Paper & 161.67 & 82.65 & $P<0.01$ \\
& Hypermedia & 49.67 & 24.15 & \\
Mechanical & Paper & 113.33 & 31.26 & $P<0.001$ \\
& Hypermedia & 41.00 & 28.71 & \\
All tasks & Paper & 137.5 & 65.52 & $P<0.001$ \\
& Hypermedia & 45.33 & 26.12 & \\
\hline
\end{tabular}

\subsection{Apprentice usability trial}

The apprentice usability trial was designed to investigate if the hypermedia system could be effective in helping someone who is unfamiliar with fine detail of the process line and its information system. The apprentices were trained to a level that ensured that they were familiar with the equipment and terminology used across the company. The same tasks and questionnaires were used as in the other usability trials. Prior to the trials the apprentices undertook a brief familiarisation of the line, its current information systems, and the hypermedia resources. The apprentices undertook all six tasks.

The apprentice, who carried out the tasks using the paper-based system first, was unable to complete electrical tasks 1 and 3. However, he was able to finish all the required tasks using the hypermedia system. The inability to complete the tasks was due to the apprentice's unfamiliarity with the paper-based system. A second apprentice (who used the hypermedia system first) was able to complete the paper-based tasks, but required some guidance.

Table 10

Task usability data from second usability trial

\begin{tabular}{|c|c|c|c|c|c|}
\hline & & Mean & $\sigma$ & Median & Significance \\
\hline \multirow[t]{2}{*}{ Documents visited } & Paper & 12.00 & 5.10 & 11.0 & \multirow[t]{2}{*}{$P<0.001$} \\
\hline & Hypermedia & 5.00 & 1.85 & 5.0 & \\
\hline \multirow[t]{2}{*}{ Time spent on location and studying each document } & Paper & 12.33 & 4.59 & 11.2 & \multirow[t]{2}{*}{$P<0.05$} \\
\hline & Hypermedia & 8.90 & 3.57 & 7.9 & \\
\hline \multirow[t]{2}{*}{ Number of occasions the user became lost } & Paper & 0.33 & 0.49 & 0 & - \\
\hline & Hypermedia & 0 & 0 & 0 & - \\
\hline \multirow[t]{2}{*}{ Number of short cuts and indexes used } & Paper & 2.50 & 2.20 & 2.0 & - \\
\hline & Hypermedia & 2.67 & 1.04 & 2.0 & - \\
\hline Links used & Hypermedia & 3.11 & 1.57 & 3.0 & - \\
\hline
\end{tabular}

Table 11

Summary of the questionnaire response after the second usability trial

\begin{tabular}{llcl}
\hline Question & Total scores & & Significance \\
\cline { 2 - 4 } & Paper & Hypermedia \\
\hline I would want to use it on a regular basis & -2 & 6 & $P<0.001$ \\
It was not frustrating to use & -6 & 6 & $P<0.001$ \\
I found it straightforward to get information & -6 & 6 & $P<0.001$ \\
There are too many steps required to get information & -6 & 6 & $P<0.001$ \\
It would not get in the way of the task I was undertaking & -7 & 6 & $P<0.001$ \\
I did not find it difficult to obtain the information & -7 & 6 & $P<0.001$ \\
I did not become lost or disoriented when using the system & -2 & 6 & $P<0.001$ \\
Total & -36 & 42 & 1.00 \\
Normalised & -0.83 & 4 \\
\hline
\end{tabular}


Table 12

Results from the apprentices usability trial

\begin{tabular}{lcrll}
\hline Media & Total time & Mean & $\sigma$ & Significance \\
\hline Paper & 1554 & 155.4 & 69.1 & $P<0.001$ \\
Hypermedia & 518 & 43.2 & 32.1 & $P<0.001$ \\
\hline
\end{tabular}

Table 13

Apprentices' usability trial data

\begin{tabular}{llrrl}
\hline & & Total & Mean & $\sigma$ \\
\hline Documents visited & Paper & 184 & 15.17 & 4.5 \\
& Hypermedia & 54 & 4.50 & 1 \\
Number of occasions & Paper & 5 & 0.42 & 0.51 \\
the user became lost & Hypermedia & 0 & 0 & 0 \\
Number of short cuts & Paper & 61 & 5.08 & 3.78 \\
and indexes used & Hypermedia & 26 & 2.17 & 0.39 \\
Links used & Hypermedia & 42 & 3.67 & 1.37 \\
\hline
\end{tabular}

Both apprentices completed all the tasks using the hypermedia system much quicker than with the paperbased system, again in approximately one-third of the time (Table 12). They also found the paper-based system difficult to use, this was demonstrated by the number of documents visited, the number of occasions they got lost (Table 13). They found the paper documentation difficult to use, partly due to unfamiliarity and the lack of proper description given to manuals. Hence, these results suggest that the hypermedia system may also be appropriate for training or induction of personnel to an unfamiliar process line. However, the sample is too small to make any general conclusions.

\section{Discussion}

\subsection{Evaluation results}

The results show that there is a statistically significant difference between using the existing paper information system and the hypermedia system developed as part of this project. That is, the users were able to find the information in approximately one-third of the time when using the hypermedia system, they had to visit less documents, and got lost less often. In addition, the questionnaire responses showed that the users significantly preferred the hypermedia system to the existing paper information system. The results from the trials using the apprentices showed that the hypermedia system may also be appropriate for training or induction of personnel to an unfamiliar process line.

\subsection{Evaluation of the methodology}

This paper has discussed the development of a methodology to evaluate industrial hypermedia applications for use on the factory floor. The evaluation of the methodology raised a number of points:

- The use of discounted usability evaluation proved to be a quick and cost-effective technique to finding usability problems during the design and prototyping phase.

- The evaluation of the methodology concluded that to use the discounted usability evaluation required the extra principle of provide navigational aids, to explicitly examine the navigational functions of the hypermedia application as seen by the users on the factory floor.

- The discounted usability evaluation process also proved to be a useful method for the line management and users to gain ownership of the application as it developed. Similarly, the results from the questionnaires suggest that performing the usability trials enabled the users to experience the advantages of using a hypermedia application at an early stage.

- Due to the nature of the evaluation process, the evaluator requires limited direct training of evaluation techniques, as the process is easily followed. The use of evaluators experienced in the application domain is considered an advantage.

- The method used was flexible and did not rely on a user carrying out the evaluations at a specific time or away from their normal workplace.

While the reported evaluation concentrated on a single application, it is our view that the evaluation methodology is relatively generic, and can be applied to other applications with only minor modification.

\subsection{Concluding comments}

The user evaluation of the large-scale industrial strength hypermedia application presented in this 
paper has focused on the experiences of the factory floor users. The evaluation process was constrained by the realistic premise that the resources of time and personnel available to participate and conduct the evaluation were limited. The approach presented moves away from the technique of using a traditional usability laboratory and presents a general method of user evaluation that can be carried out in and by personnel from the industrial environment.

The results demonstrate that open hypermedia technology can effectively combat the twin problems of information overload and information deprivation found in many industrial situations while navigating a disparate information space. It is our intention to take this work forward and examine the impact of hypermedia information systems on the ability of the users to undertake their tasks.

\section{Acknowledgements}

The authors acknowledge our industrial partners for allowing their personnel to take part in the trials, and the Engineering and Physical Science Research Council for funding the work under Grant Number GR/L/10482. The authors fully acknowledge the contribution made to this work by Dr. I. Heath. The contribution to this research by the staff and management at Pirelli Cables, Eastleigh and The Ford Motor Company, Southampton is acknowledged.

\section{Appendix A. Questionnaire used after a training}

Impression

The system is one that I would want to use on a regular basis.

The system was very demanding and not enjoyable to use.

This high-tech route to information is intimidating.

The system was frustrating to use.

I would recommend this system to my colleagues.

I enjoyed working with this system.

This system was really very awkward to use.

Command

The system was responsive to my inputs.

I did not find it easy to start the application.

I felt I had no control over the system.

The system did not respond quick enough to my selections.

If the system stopped working it was not easy to restart it.

It was easy to make the system do exactly as I wanted.

Effectiveness

To get to the information I needed was straightforward.

Using the system hindered the task I was undertaking.

I was not able to find the information I required.

There are too many steps required to get to the information.

Navigability

It was easy to move around the information.

There were plenty of ways to find the information I needed.

The toolbar provided useful short cuts.

I could find my way around the information using the menus and content pages.

It is easy to become disoriented when using the system. 


\section{Appendix A. (Continued)}

\section{Learnability}

I felt safer when using only the method I was familiar with to find the information.

The guidance given before using the system, was enough to use the system.

I felt safe trying different ways to get to the information.

Learning to use the system was easy.

\section{Aidability}

The system was helpful in coping with the error.

The system help files provide enough information.

I was unsure if I was using the right command.

There was not enough information displayed on how to respond/proceed.

I found the system awkward to use if I wanted to do something out of the ordinary.

I could not understand or act on the information provided by this system.

\section{Comprehension}

The information was clearly presented and understandable.

The information displayed was inconsistent.

The actions associated with the buttons on the main toolbar were easily understood.

The screens became cluttered and confusing.

I understood the action of the window's tools bars.

I understood how to operate the system.

To get to the relevant information I had to scroll down the page.

The layout of the manuals was satisfactory.

The buttons were clearly visible in drawings.

Too much text was displayed at any one time.

\section{Appendix B. Questionnaire used after a usability trial}

\section{Impression}

I prefer to use the paper-based system regular.

This high-tech route to information is intimidating.

The computer-based system was frustrating to use.

I found that the paper-based system was awkward to use.

The computer-based system is one that I would want to use on a regularly basis.

I enjoyed working with the computer-based system.

I would recommend the computer-based system to my colleagues.

\section{Command}

It was able to make the computer-based system do exactly as I wanted.

The computer-based system did not react quick enough to my selections.

I did not have complete control over the system.

The system was responsive to my inputs.

\section{Effectiveness}

To get to the information I needed in the paper-based system was straightforward.

In the paper-based system I had to go through many steps to get to the information.

Using the paper-based system hindered the task I was undertaking. 
Appendix B. (Continued)

When using the paper-based system I found it difficult to obtain the information I needed.

In the computer-based system there are too many steps required to get to the information.

In the computer-based system I found it straightforward to get to the information.

Using the computer-based system would get in the way of the task I was undertaking.

When using the computer-based system I found it difficult to obtain the information I needed.

Navigability

I frequently did not know where to go next with the paper-based system.

I was able to move around the computer-based information easily. The computer-based toolbar provided useful short cuts.

I did not find the computer-based menus and content pages useful.

I often become lost/disoriented when using the computer-based system.

There were plenty of ways to find the information I needed.

\section{Learnability}

Learning to use the system was easy.

I felt safer when using only the method I was familiar with to find the information.

The guidance given before using the system, was enough to use the system.

I felt safe trying different ways to get to the information.

\section{Aidability}

The system messages were helpful in coping with the error.

I understood and was able to act on the messages provided by this system.

The system was awkward to use if I wanted to do something out of the ordinary.

I was unsure if I was using the right command.

The system help files provided enough information. There was not enough information displayed on how to respond/proceed.

\section{Comprehension}

The actions associated with the buttons on the main toolbar were easily understood.

I did not understand the action of the window's tools bars.

I understood how to operate the system.

The information was clearly presented and understandable.

The information displayed was inconsistent.

The layout of the manuals was satisfactory.

The buttons were clearly visible in drawings.

Too much text was displayed at any one time.

To get to the relevant information I had to scroll down the page.

The screens became cluttered and confusing.

\section{References}

[1] K. Malcolm, S. Poltrock, D. Schuler, Industrial strength hypermedia: requirements for a large engineering enterprise, in: Proceedings of the Hypertext'91, Seattle, 1991, pp. 13-24.

[2] R. Crowder, G. Wills, I. Heath, W. Hall, Hypermedia information management: a new paradigm, in: Proceedings of the Third International Conference on Managing Innovation in Manufacture, University of Nottingham, 1998, pp. 329334.

[3] R. Crowder, W. Hall, I. Heath, G. Wills, Industrial strength hypermedia: design, implementation and application, International Journal of Computer Integrated Manufacturing 13 (3) (2000) 173-186.

[4] D. Fakun, R. Greenough, User-interface design heuristics for developing usable industrial hypermedia applications, Human 
Factors and Ergonomics in Manufacturing 12 (2) (2002) 127-149.

[5] H. Ip, K. Law, S. Chan, An open framework for a multimedia medical document system, Journal of Microcomputer Applications 18 (1995) 215-232.

[6] A. Dunlop, M. Papiani, A. Hey, Providing access to a multimedia archive using the World Wide Web and an objectrelational database management system, IEE Computing and Control 7 (5) (1996) 221-226.

[7] P. De Bra, Pros and cons of adaptive hypermedia in Webbased education, Cyberpsychology and Behavior 3 (1) (2000) $71-77$.

[8] G. Wills, Design and evaluation of industrial hypermedia, Ph.D. Thesis, Department of Electrical Engineering, University of Southampton, 2000.

[9] R. Crowder, W. Hall, I. Heath, G. Wills, Factory information provision using hypermedia, International Journal of Computer Applications in Technology 11 (1998) 442-453.

[10] H. Davis, W. Hall, I. Heath, G.H.R. Wilkins, Towards an integrated environment with open hypermedia systems, in: Proceedings of the ACM Conference on Hypertext, EHCT'92, Milan, Italy, 1992, pp. 181-190.

[11] I. Heath, W. Hall, R. Crowder, G. Wills, J. Ballantyne, A new authoring methodology for large-scale hypermedia applications, Multimedia Tools and Applications 12 (2/3) (2000) 129-144.

[12] R. Crowder, W. Hall, I. Heath, G. Wills, Integration of manufacturing information using open hypermedia, Computers in Industry 38 (1) (1999) 31-42.

[13] W. Hall, M. Weal, I. Heath, G. Wills, R. Crowder, Flexible interfaces in the industrial environment, in: Proceedings of the Conference on Managing Enterprises-Stakeholders Engineering Logistics and Achievement (ME-SELA'97), Loughborough, UK, 1997, pp. 453-460.

[14] J. Preece, et al., To Usability: Human Factors in Computing, Addison-Wesley, Reading, MA, USA, 1993.

[15] A. Dix, J. Finaly, G. Abowd, R. Beale, Human-Computer Interaction, Prentice-Hall, New Jersey, 1998.

[16] J. Preece, Y. Rogers, H. Sharp, D. Benyon, S. Holland, T. Carey, Human-Computer Interaction, Addison-Wesley, Reading, MA, USA, 1994.

[17] N. Fenton, S. Pfleeger, Software Metrics: A Rigorous and Practical Approach, second ed., PWS Publishing Company and International Thomson Computer Press, London, 1997.

[18] V. Basili, G. Cadiera, H. Rombach, Goal-question-matrixapproach, Encyclopaedia of Software Engineering, Wiley, New York, 1994, 523-528.

[19] L. Hsu, P. Liu, T. Dawidowsky, A multimedia authoring-inthe-large enviroment to support complex product documents, Multimedia Tools and Applications 8 (1) (1999) 11-64.

[20] T. Kosky, A. Gramopadhye, W. Kennedy, N. Ramu, Application of hypertext technology to assist maintenance on the shop floor, Computer and Engineering 30 (2) (1996) 283-295.

[21] D. Fankun, R. Greeenough, The relevance of a maintenance hypermedia application to concurrent engineering, in: Proceedings of the 15th National Conference on Manufacturing Research, Bath, UK, 1999, pp. 401-405.
[22] F. Davis, A critical assessment of potential measurement biases in the technology acceptance mode: three experiments, International Journal of Human Computer Studies 45 (1996) 19-45.

[23] F. Garzotto, P. Paolini, Systematic evaluation of hypermedia applications, Tutorial at The Eighth ACM Conference on Hypertext, Southampton, UK, April 6-11, 1997.

[24] S. Yamada, J. Hong, S. Sugita, Development and evaluation of hypermedia for museum education: validation of metrics, ACM Transactions on Computer-Human Interaction 2 (4) (1995) 284-307.

[25] K. Höök, Evaluating the utility and usability of an adaptive hypermedia system, Journal of Knowledge-Based Systems 10 (5) (1998) 311-319.

[26] J. Nielsen, Usability engineering at a discount, in: G. Salvengy, M.J. Smith (Eds.), Designing and Using HumanComputer Interfaces and Knowledge Based Systems, Elsevier, Amsterdam, 1989, pp. 394-401.

[27] R. Molich, J. Nielson, Improving a human-computer dialogue, Communications of the ACM 33 (3) (1990) 338346.

[28] J. Nielsen, Finding usability problems through heuristic evaluation, in: P. Bauersfeld (Ed.), Proceedings of Human Factors in Computing Systems, CHI'92, ACM Press, New York, 1992, pp. 373-380.

[29] J. Kirakowski, M. Corbett, SUMI: the software usability measurement inventory, British Journal of Educational Technology 24 (3) (1993) 210-212.

[30] A. Smailagic, B. Bennington, Wireless and mobile computing in train maintenance and diagnosis, in: 47th Annual International Conference, vol. 3, IEEE Vehicular Technology Society, Phoenix, AZ, 1997, pp. 1932-1936.

[31] R. Crowder, Y. Sim, G. Wills, R. Greenough, A review of the benefits of using hypermedia manuals, in: Proceedings of the 12th ACM Conferences on Hypertext and Hypermedia, Arhus, Denmark, 2001, pp. 245-246.

[32] G. Hill, G. Hutchings, R. James, S. Loades, J. Hale, M. Hatzopulous, Exploiting serendipity amongst users to provide support for hypertext navigation, in: Hypertext'97, Southampton, UK, April 6-11, 1997, pp. 212-221.

[33] J. Foster, Data Analysis using SPSS for Windows: A Beginners Guide, Sage, Beverley Hills, CA, USA, 1998.

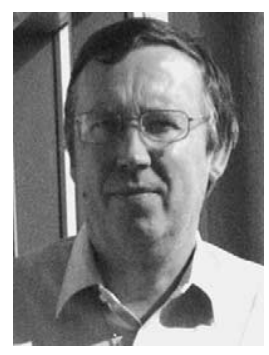

Richard Crowder is currently senior lecturer in robotics and control in the Department of Electronics and Computer Science, University of Southampton. $\mathrm{He}$ joined the Intelligence, Agents, Multimedia Group from the Department of Electrical Engineering, to develop his interests in the industrial applications of knowledge technology. He currently is undertaking research into expertise finders within the engineering design environment. He obtained his $\mathrm{PhD}$ in electrical engineering from the University of Leicester in 1977. Prior to joining the University of Southampton, he worked in the machine tool industry, 
specialising in high-performance systems for the aerospace industry. He has additional research interests in biologically inspired robotics systems, with particular reference to manipulation. Richard has authored approximately 70 refereed journal and conference papers. He has supervised a number of successful $\mathrm{PhD}$ candidates. $\mathrm{He}$ is a chartered engineer and a member of the Institution of Electrical Engineers.

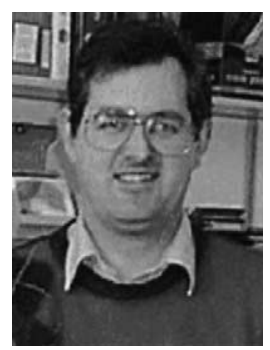

Gary Wills is a senior research fellow in the Intelligence, Agents, Multimedia Group within the Department of Electronics and Computer Science at the University of Southampton. He holds a $\mathrm{PhD}$ for research into the design and evaluation of industrial hypermedia from the University of Southampton. He currently undertakes research into advance knowledge technologies and open-hypermedia design, particularly for industrial, educational and medical applications. He has published over 20 academic papers.

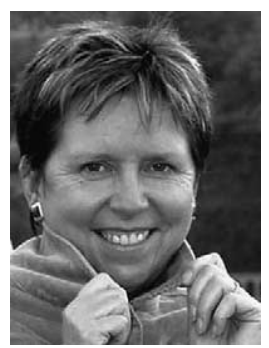

Wendy Hall is professor of computer science at the University of Southampton, UK. She was the founding head of the Intelligence, Agents, Multimedia Group in the Department of Electronics and Computer Science at Southampton and is currently the Head of Department. Her research interests include the development of multimedia information systems and their applications in education, industry and commerce, open hypermedia systems and link services, digital libraries, multimedia databases, content-based retrieval, agent systems and user interfaces. She regularly speaks at international conferences, and is a member of a number of editorial boards of journals in her research area, including IEEE MultiMedia, the Computer Journal and JoDI. Wendy was awarded a CBE in the Queen's Birthday Honours list in June 2000, and became a Fellow of the Royal Academy of Engineering in the same year. In addition, Wendy is a Fellow of the British Computer Society and a Fellow of the Institution of Electrical Engineers. 